\title{
NARRATIVAS GAYS: TECNOLOGIA DA NORMALIDADE E A VIOLÊNCIA SIMBÓLICA
}

Alexandre Luiz Polizel

Universidade Estadual de Londrina - UEL, Programa de Pós-graduação em Ensino de Ciências e Educação Matemática, Londrina, PR. E-mail: alexandre_polizel@hotmail.com

\section{RESUMO}

Este manuscrito tem por objetivo apresentar analíticas da tecnologia da normalidade que atravessa a trajetória de vida dos corpos gays em espaços educacionais. Para isso, lança-se mão das teorizações heteroautobiográficas, utilizando de entrevista semiestruturada vertidas as produções de narrativas de dois licenciandos que se (auto)identificam gays, vinculados a Universidade Estadual de Maringá, Maringá, Sul do Brasil. A analítica deu-se sob análise de discurso inspirada no teórico Michel Foucault, utilizando do conceito de tecnologias de poder e resistência como fios condutores desta hermenêutica. Evidenciou-se nas narrativas de ambos os sujeitos, a operação de uma tecnologia da normalidade atrelada as violências simbólica que atravessavam seus corpos.

Palavras-Chave: Narrativa de si, Identidade, Normalização.

\section{NARRATIVE GAYS: TECHNOLOGY OF NORMALITY AND SYMBOLIC VIOLENCE}

\begin{abstract}
This manuscript aims to present analytics of the technology of normality that crosses the life trajectory of the gay bodies in educational spaces. In order to do so, we use the heteroautobiographic theorizations, using a semi-structured interview, the narrative productions of two graduates who (self)identify gays, linked to the State University of Maringá, Maringá, Southern Brazil. The analytic took place under discourse analysis inspired by the theorist Michel Foucault, using the concept of technologies of power and resistance as guiding threads of this hermeneutics. It was evidenced in the narratives of both subjects, the operation of a technology of normality tied to the symbolic violence that crossed their bodies.
\end{abstract}

Keywords: Self-narrative, Identity, Standardization. 


\section{PERCURSOS}

O presente trabalho consiste em um recorte constituinte de uma investigação maior intitulada: Histórias, violências e desalojares: A trajetória de LGBTs nos espaços de ensino. Neste manuscrito temos por objetivo apresentar considerações acerca da "tecnologia da normalidade" e tecnologias de resistências que atravessam os corpos gays em sua trajetória pelos espaços de ensino.

Assim, retomo meu olhar ao questionamento mote dessa investigação: "Que perceptos de violências atravessam e compõem um corpo gay nos espaços de ensino?". Problematização esta que considera um percurso, um transito por instituições que requerem a si a validação de seu operante por ser um espaço educacional. Esses consistem em locais formativos, que analisam, organizam e elegem saberes como formativos ou não. Essa eleição de saberes, requer então para si um estatuto de verdade, ou seja, legitimar-se como saber verdadeiro - e por isso formativo em detrimento a outros, instaurando um quadro de referências a ser seguido (FOUCAULT, 2015; 2014).

O quadro de referências não estabelece-se e subsiste por si, ele necessita de constante investimento para mantê-lo como norma vigente. Este investimento requer um conjunto de técnicas e tecnologias, que consistem em modos de produção, que atravessam os corpos e os constituem - as chamadas tecnologias de poder - via ajustamento de condutas. Assim, o quadro de referências instaura-se, à medida que produz o sujeito operante e reiterante deste, estabelecendo códigos de condutas de um ser "forma(ta)do". Todavia, as tecnologias de poder e formatação dos sujeitos não são absorvidas em sua totalidade, mas são negociadas, torcidas, tracionadas, deslocadas a medida que encontram tecnologias de resistência (FOUCAULT, 2015; 2014; BUTLER, 2015b).

Leandro Colling (2015) traça considerações de que as tecnologias de poder em movimento no ocidente contemporâneo, encontram-se articuladas em um dispositivo de sexualidade, que tem funcionado por uma lógica (cis)heteronormativa, ou seja, que estabelece como o modo de existir, representante de uma normalidade eleita, o ser cisgênero e heterossexual. Este quadro, leva a incidências de tecnologias de poder sob os corpos, afim de formata-los e induzi-los a operar nesta lógica - (cis)heterossexual -, classificando-os como: a) normais, em consonância com a normalidade estabelecida no quadro de referências da (cis)heteronormatividade; ou b) (des)viados, em dissonância a este quadro. As investidas de poder sob tentativas de (re)adequar os (des)viados a norma, refletem em violações a estes corpos.

É neste percurso, que retomamos nosso questionamento: "Que perceptos de violências atravessam e compõem um corpo gay nos espaços de ensino?". Para traçar considerações acerca deste questionamento e, da tecnologia da normatividade evidenciada em nossa analítica, organizamos este manuscrito em dois eixos: a) Narrativações, apresentando a trajetória metodológica; b) Tecnologia da normalidade e a violência simbólica, em que apresentamos a taxonomização ${ }^{1}$ desta tecnologia.

\section{NARRATIVAÇÕES}

Narrativas... processos enunciativos, que como processos encontram-se em constante (des)constituição: em Narrativações. Estas narrativas dão-se em cacos, em partes constituintes que são montadas e produzem uma forma - um modo de ser, estar, pensar e existir. Esta formação, via narrativação, é por si uma arte, uma produção de modos possíveis. Assim, ao buscar narrativações, encontramo-nos buscando por peças constituintes dos sujeitos, que possibilitam assim pensar sua constituição, as forças que os atravessam e seus desejos. O trabalho de constituição dessas narrativações requer, assim um local de fala, que só é possível a medida que

\footnotetext{
1 Utilizamos taxonomia em um sentido de classificação, de trazer uma descritiva-analítica sob um determinado fenômeno, atribuindo-o uma nomenclatura que permite uma referenciação desta descritiva.
} 
Ihe é produzido também um espaço de escuta (BUTLER, 2015a). Neste espaço instaurado, buscase falar de si, confessar-se e até mesmo guardar segredos sobre si a medida que não se enuncia. Assim, nas narrativações são produzidos corpos híbridos, daqueles que narram-se e dos que escutam e reconhecem este. É a este percepto, das narrativações, do contar-se e constituir-se que Margareth Rago (2013) trata como heteroautobiográfia.

A heteroautobriografia consiste em um movimento, de deslocamentos, reconhecimentos e fraturas, um processo que é nômade e, faz-se: a) hetero visto que envolve dois corpos diferentes em encontro; b) biográfico visto que um corpo produz narrativas sobre suas experiencialidades, memórias, e relações espaço-temporais; c) autobiográfica visto que aquele que escuta e reconhece o outro, mistura suas experiencialidades ao criar um espaço de escuta e ao produzir registros deste encontro; e d) heteroautobiográfica, visto que as narrativações, as memórias, os reconhecimentos, escutas e registros, produzem enunciados e constituem a existência de ambos (RAGO, 2013).

É neste processo de produção de narrativas, de experiências enunciadas, que estas vivencias são trazidas ao presente e mostram-se, extrapolando sensações, sentidos, e marcas deixadas nos corpos nos encontros deste com os exercícios das tecnologias de poder. Nestes encontros com as tecnologias de poder, as marcas não são apenas gravadas por esta, mas são marcas dos embates, das resistências, trações, negociações. Assim, as marcações mobilizadas nas narrativações envolvem uma possibilidade de diagnose destas histórias de vidas não lineares, presentificadas e (re)(des)subjetivadas, permitindo atribuir novos sentidos a este percurso. Assim, é possível taxonomizar tais tecnologias de poder, reconhece-las, (des)(re)memora-las e até mesmo refaze-las no processo do relatar a si (BUTLER, 2015a; RAGO, 2013). Deste modo, tecnologias de poder e resistência são evidenciadas, deixadas mostrar, e oferecem também o testemunho de possibilidades de novos possíveis caso novos encontros com estas.

Considera-se ainda, que as tecnologias do poder que incidem sobre os corpos reinvindicam a produção de estatutos de verdades, de quadros de referências e, ao encontrar estes corpos buscam molda-los via processos de subjetivação-sujeição este. E estes corpos reagem a estas incidências, via tecnologias de resistência, requerendo negociação dos sentidos e dos modos de existência (FOUCAULT, 2015; 2014).

Neste sentido, as narrativas produzidas e as marcas carregadas por eles via a perspectiva heteroautobiográfia, criam lacunas para que vertemos a elas nosso olhar e, com instrumentos de diagnose produzamos saberes acerca dos corpos gays que fazem-se narrar acerca das (re)memorações de sua trajetória nos espaços educacionais (RAGO, 2013).

Neste sentido, buscou-se a produção das narrativações não presentes no registro oficial dos espaços educacionais escolares, mas sim em corpos desviantes a (hetero)norma. Utilizou-se então como mote de busca das produções de narrativas dois critérios, vertendo o exercício da escuta e produções a: a) estudantes locados em cursos de licenciatura da Universidade Estadual de Maringá (UEM), Paraná; e b) que se autoidentificavam como pertencentes a categoria de minorias sexuais (Lésbicas, Gays, Bissexuais, e pessoas Trans).

Os sujeitos foram selecionados por conveniência, buscando voluntários que participassem em grupos de estudo relacionado a temática de gênero e sexualidades, movimentos sociais estudantis e indicações de colegas. Convites foram encaminhados, marcando um diálogo pessoalmente, em uma sala da universidade - convite foi realizado pessoalmente ou por meio de redes sociais. Antes de iniciar a conversa foi apresentado um Termo de Consentimento Livre Esclarecido $^{2}$, bem como as questões guias que norteariam o diálogo e a contação de suas narrativas de vida. Este diálogo que o que permitia a constituição dos retalhos narrativos.

O diálogo foi guiado por uma entrevista oral, sendo utilizado perguntas guias como eixo norteador, sendo assim: a) audiogravadas e transcritas, bem como b) tomadas notações em

\footnotetext{
2 Procedimento aprovado no Conselho de Ética e Pesquisa com Seres Humanos da UEM, sob no CAAE 55404015.5.0000.0104
} 
caderno de campo, para percepções e sensações pessoais (RAGO, 2013; CANTANI, 2006). Perguntas abertas foram utilizadas para direcionamento no processo de relatar-se e (re)memorarse, sendo: a) Frente as violências contra as minorias sexuais de gênero, temos desde agressões físicas, psicológicas à simbólicas. Sob tais aspectos e frente a sua história de vida, o que você compreende como violência? b) Em um cenário onde a evasão da educação básica de indivíduos LGBTs tem sido recorrente em nosso pais, você em sua passagem pela educação básica já sofreu violência? c) Poderia nos relatar histórias destas violências de vida e comentar se estas influenciavam no seu processo de ensino e aprendizagem e ocupação destes espaços de educação básica? d) Em um contexto de ensino superior, que você ocupa você acredita que a violência para com LGBTs tem sido ocorrente? e) Você como membro desta minoria sexual, já sofreu violência? De que forma essa ocorrência influenciou na sua relação com o lugar que você ocupa? f) No que toca a sua história de vida, frente aos apagamentos realizados no Plano Nacional de Educação, qual sua sensação?

Estes retalhos, eleitos para serem narrados, consistem em uma tradução seletiva para a presentificação e constituição do eu, e após audiogravados e transcritos, tiveram lançados sobre eles inclinados uma hermenêutica baseada em minha tecnologia de ouvir e de olhar, inspirada em teorizações de Michel Foucault e sua ressonâncias (2015; 2014; 1996; FISCHER, 2001), bem como a perspectiva heteroautobiográfica de Margareth Rago (2013).

Destarte, os relatos produzidos e apresentados aqui deram-se nos encontros com dois corpos, atravessados por múltiplas categorias identitárias, sendo:

a) Renato ${ }^{3}$, apresentando-se como um homem cisgênero homossexual, afeminado, e bem acima do peso. Licenciando do último ano de química pela Universidade Estadual de Maringá (UEM), Paraná, Sul do Brasil. Envolvido com projetos filantrópicos e com o Programa Institucional de Bolsas de Iniciação à Docência em química.

b) Gabriel (auto)identifica-se como um menino de 20 anos, gordo, afeminado, licenciando do terceiro ano do curso de ciências biológicas pela Universidade Estadual de Maringá (UEM). Este é envolvido com projetos associados a empresas juniores da área ambiental e, com Programas Institucionais de Bolsas de Iniciação Científica.

\section{TECNOLOGIA DA NORMALIDADE E A VIOLÊNCIA SIMBÓLICA}

Narrativações são produzidas... Elas emanam, e quando alguém escreve é porque Outro tem algo a dizer. Vemos em ambas as narrativas enunciadas pelos corpos gays com quem nos encontramos, de Renato e Gabriel, a grande preocupação de seus corpos em consonância com um regime de normalidade. A exemplo representativo, segue um recorte relatado:

Bom, eu acho que... para mim... violência é quando você foge do que é considerado padrão, normal, e uma pessoa usa isso como uma forma de te diminuir, de qualquer forma possível, seja fisicamente né!? Quando envolve agressões físicas. Ou moralmente, ou até mesmo no campo de trabalho, por exemplo, quando dizem "Ah, você é gay, não vou prestar atenção no que você está falando por que você não sabe o que você está dizendo... Você não é uma pessoa normal". (RENATO)

Ambos conclamam "[...] somos pessoas completamente normais" (RENATO), "[...] seres humanos como qualquer outro" (GABRIEL). Estes são os enunciados mais presentes em suas indagações acerca de suas trajetórias pelos espaços educacionais. Corpos recortados por características identitárias consoantes: mesma faixa etária, ambos corpos gordos, homossexuais, afeminados e licenciandos no campo das ciências naturais pela mesma universidade. Ambos com

\footnotetext{
${ }^{3}$ Utilizamos de nomes fictícios afim de resguardar a integridade dos corpos que narraram-se.
} 
o mesmo clamor em suas narrativas: o requerimento de pertencimento ao quadro de normalidade.

Evidencia-se, em Michel Foucault $(2015 ; 2014)$ que a diferença produz a normalidade, ou seja, que instauram-se regimes de verdades que posicionam os sujeitos em determinada localização e, que conferem a estes corpos uma valorativa. Assim, um conjunto de enunciados e discursos produzem instauram verdades, estas por sua vez naturalizam modos de existir não naturais, estipulando o normal e o desvio, o natural e o anormal... Estas dicotomias, ao serem institucionalizadas, passam a agir como regimento, que produz o quadro de normalidade vigente.

Quadro de normalidade que só é possível pois este delineou o que é a "diferença" dentro deste. Assim, a diferença é o que mantem a normalidade em funcionamento.

Renato e Gabriel indicavam que seus corpos eram lidos como "[...] diferente na questão da orientação sexual", que "[...] não era tratado como pessoa normal" e, isso era considerado um modo um indicativo para que violências incidissem sobre seus corpos. A tentativa assim dual: a) A deslegitimação de suas discursividades, como Renato ressalta, "Qualquer coisinha falavam $A h$ você... não anda tão afeminado porque as pessoas não vão te levar a sério"; e b) A normalização, em que era arrastado a "[...] não falar disso [...], não se ver como viado", sendo levado a performar em muitos momentos padrões estabelecidos como normais.

Neste sentido, vemos operar uma tecnologia da normalidade. Esta tecnologia, como apontado por Michel Foucault $(2015 ; 2014)$ encontra-se alinhada ao estabelecimento da norma e, também a manutenção desta em funcionamento. A operação da norma, neste sentido, dar-se a medida que delineia as diferenças e assim instaura a normalidade - estabelecendo um quadro de referências. A partir deste quadro, saberes são incididos sobre os corpos e estes passam a ser (as)sujeitados. Este processo de (as)sujeitamento, no espaço escolar pode ser lido por meio dos processos disciplinares. As disciplinas consistem em buscas por instaurar modos de ser como valorados em detrimento a outros, para isso organiza-se o espaço, o tempo, os saberes e as discursividades que podem existir e circular. Os corpos que são disciplinados são adequados a norma, os que mantem-se em indisciplina, são apontados pelo quadro de referências como um modelo de "diferença" a não ser quista - marcado como um modo de ser improdutivo.

Esta diferença, que marca os corpos dos sujeitos como diferente, resvala em tentativas de (re)normatizações forçadas ou, na autorização de violência para com estes corpos que como improdutivos deixam de importar (BUTLER, 2015b). Vê-se a exemplo, que Renato e Gabriel apresentam as violências investidas em seus corpos como motes autorizados nos espaços educacionais pelos quais transitaram, seja publicamente ou mais sutis. Destaca-se:

$\mathrm{Ai}$, tanto um olhar torto, que você sabe que é direcionado a você né. Um empurrão, que você sabe que não foi sem querer. Quando tentam te derrubar sabe, e pisam em você, que você sabe que não foi sem querer também. Tanto quando te xingam abertamente, assim, verbalmente, gritam na rua. Muitas vezes. Isso é violência. [...] nunca levei assim muito essas violências a sério. Eu nunca deixei essas pequenas violências me abalar, porque eu nunca tive, sofri, uma grande violência assim, as pequenas eu não deixei abalar. [...] Então eu não digo que influenciaram não. (GABRIEL)

Os exercícios de violações para com os corpos portadores das marcas das diferenças, os diferentes, mostra-se como um fenômeno evidenciado na operação da tecnologia da normalidade (FOUCAULT, 2015; 2014), sendo investido sob o corpo físico, ou sobre a psique do sujeito. Todavia, como um quadro de normalidade vigente, este pode ser reconhecido como uma violência menor ou não violência -, como colocado por Gabriel "Eu não digo que elas (as violências) me influenciaram muito [...] nuca tive, sofri, uma grande violência assim, então as pequenas eu não me deixei abalar [...], eu nem tinha consciência", ou por Renato, que relata que "[...] nunca passou por isso (em relação as violências)". 
Evidencia-se, que em um quadro de normalidade vigente, os sujeitos-diferentes sabem identificar os tipos de violência, mas muitas vezes não reconhecem-se atravessados por estas violações - operações de tecnologias de poderes. A filósofa Judith Butler (2015a; 2015b) pontua que quando estabelecido um quadro de referências que instaura determinada normalidade, estas carregam consigo corpos classificados como produtivos ou improdutivos, imprimindo nestes importâncias. Para esta, os corpos que não importam, os diferentes, são classificados como corpos matáveis e, por isto as violências para com estes nem sempre são tratadas como tal.

O sociólogo Pierre Burdieu (1999) traz outra possibilidade ao pontuar a existência de um tipo de violência, a simbólica. Para Bourdieu os corpos são classificáveis e hierarquizados de acordo com os regimes-estruturas culturais operantes. Nestes, processos de violações para com algumas identidades relacionadas as feminilidades não são lidas como violências, pois no plano simbólico não são reconhecidas como tais visto que seu exercício encontra-se naturalizado. Assim, por simbolicamente não ser reconhecida como violência os sujeitos não percebem-se afetados por tal.

Vê-se, assim, o não reconhecimento de violações para com seus corpos, ou que as presentes estejam enquadradas como violências menores, nas narrativas de Renato e Gabriel, sujeitos gays, gordos, afeminados e licenciandos. O que sugere que o não reconhecimento destas, encontra-se alinhado a tecnologia da normalidade que posicionam seus corpos como "diferentes" e, assim, elege-os como corpos que não importam e naturalizam estas violações. Vê-se neste sentido que a instauração de quadros de referências e, com estas, o estabelecimento de padrões de normalidade e posicionamento de sujeitos, produzam-se culturas-estruturas-regimes que delineiam a produtividade dos corpos, sua importância e as violências que serão naturalizadas como não violências - e (não) reconhecidas no plano simbólico.

\section{REFERÊNCIAS}

BOURDIEU, P. A dominação masculina. Rio de Janeiro: Bertrand Brasil, 1999.

BUTLER, J. Relatar a si mesmo: crítica à violência ética. Belo Horizonte: Autentica Editora, 2015a

. Corpos que pensam: sobre os limites discursivos do "sexo. In: LOURO, Guacira Lopes

(Orgs). O corpo educado: pedagogias da sexualidade. Belo Horizonte: Autêntica Editora, 2015b

CATANI, D.B. Autobiografia como saber e a educação como invenção de si. In SOUZA, E.C.; ABRAHÃO, M.H.M.B. (Orgs) Tempos, narrativas e ficções: a invenção de si. Porto Alegre: EdiPUCRS, 2006, p.77-87

COLLING, L. O que perdemos com os preconceitos? Revista Cult, 202, ano 18, 2015, p. 22-25

FISCHER, R.M.B. Foucault e a análise de discurso em educação. Cadernos de Pesquisa, (114), 2001, p.197-223

FOUCAULT, M. História da sexualidade I: A vontade de saber. 3 ed. São Paulo: Paz e Terra, 2015 . Vigiar e punir: Nascimento da prisão. 42 ed. Petrópolis-RJ: Vozes, 2014

RAGO, M. A aventura de contar-se: Feminismos, escrita de si e invenções da subjetividade. Campinas, SP: Unicamp, 2013 